\title{
Article \\ Hydrophobic Modification of Graphene Oxide and Its Effect on
the Corrosion Resistance of Silicone-Modified Epoxy Resin
}

Wei Yuan ${ }^{1,2}$, Qian $\mathrm{Hu}^{1,2, *}$, Jiao Zhang ${ }^{1,2}$, Feng Huang ${ }^{1,2, *}$ and Jing Liu ${ }^{1,2}$

1 State Key Laboratory of Refractories and Metallurgy, Wuhan University of Science and Technology, Wuhan 430081, China; yuanwei_wust@sina.com (W.Y.); zj2020wust@163.com (J.Z.); liujing@wust.edu.cn (J.L.)

2 Hubei Engineering Technology Research Center of Materials and Service Safety, Wuhan University of Science and Technology, Wuhan 430081, China

* Correspondence: huqian@wust.edu.cn (Q.H.); huangfeng@wust.edu.cn (F.H.)

Citation: Yuan, W.; Hu, Q.; Zhang, J.; Huang, F.; Liu, J. Hydrophobic

Modification of Graphene Oxide and Its Effect on the Corrosion Resistance of Silicone-Modified Epoxy Resin. Metals 2021, 11, 89. https://doi.org/ $10.3390 /$ met11010089

Received: 19 November 2020 Accepted: 30 December 2020 Published: 5 January 2021

Publisher's Note: MDPI stays neutral with regard to jurisdictional clai$\mathrm{ms}$ in published maps and institutional affiliations.

Copyright: $\odot 2021$ by the authors. Licensee MDPI, Basel, Switzerland. This article is an open access article distributed under the terms and conditions of the Creative Commons Attribution (CC BY) license (https:// creativecommons.org/licenses/by/ $4.0 /)$.

\begin{abstract}
This study modified graphene oxide (GO) with hydrophilic octadecylamine (ODA) via covalent bonding to improve its dispersion in silicone-modified epoxy resin (SMER) coatings. The structural and physical properties of ODA-GO were characterized by field-emission scanning electron microscopy (FE-SEM), X-ray diffraction analysis (XRD), Fourier transform infrared spectroscopy (FT-IR), Raman spectroscopy, X-ray photoelectron spectroscopy (XPS), and contact angle tests. The ODA-GO composite materials were added to SMER coatings by physical mixing. FE-SEM, water absorption, and contact angle tests were used to evaluate the physical properties of the ODA-GO/SMER coatings, while salt spray, electrochemical impedance spectroscopy (EIS), and scanning Kelvin probe (SKP) methods were used to test the anticorrosive performance of ODA-GO/SMER composite coatings on Q235 steel substrates. It was found that ODA was successfully grafted onto the surfaces of GO. The resulting ODA-GO material exhibited good hydrophobicity and dispersion in SMER coatings. The anticorrosive properties of the ODA-GO/SMER coatings were significantly improved due to the increased interfacial adhesion between the nanosheets and SMER, lengthening of the corrosive solution diffusion path, and increased cathodic peeling resistance. The $1 \mathrm{wt} . \%$ ODA-GO/SMER coating provided the best corrosion resistance than SMER coatings with other amounts of ODA-GO (including no addition). After immersion in $3.5 \mathrm{wt} \% \mathrm{NaCl}$ solution for 28 days, the low-frequency end impedance value of the $1 \mathrm{wt} . \%$ ODA-GO/SMER coating remained high, at $6.2 \times 10^{8} \Omega \cdot \mathrm{cm}^{2}$.
\end{abstract}

Keywords: graphene oxide; octadecylamine; silicone-modified epoxy resin; scanning Kelvin probe; electrochemical impedance spectroscopy

\section{Introduction}

The economic losses caused by metal corrosion are huge. Coating metals with organic polymers is one of the most common anticorrosive measures [1,2]. In the anticorrosion field, the application of silicone-modified epoxy resin (SMER) is developing rapidly. For example, Kumar et al. [3] found that composite coatings consisting of epoxy resin and silicone polymer have high hydrophobicity and corrosion resistance. In the present study, SMER was used as an organic film-forming agent for the preparation of anticorrosive coatings. However, pure SMER coatings may form defects, such as micropores, during the process of solvent evaporation, which can weaken their corrosion resistance. Related studies have shown that the addition of nanoparticles can effectively improve the corrosion resistance of the coating by filling defects in the coating, extending the diffusion path of the corrosive medium in the coating, and increasing the interfacial adhesion inside the coating [4-9].

Graphene oxide, a derivative of graphene, is a nanoparticle that has attracted increasing research attention for its excellent mechanical and physical properties $[10,11]$. On the one hand, the addition of graphene oxide (GO) can improve the anti-corrosion properties of polymer coatings by lengthening the diffusion path of the corrosive species and providing a good physical barrier against corroding agents [12]. On the other hand, the poor dispersion 
of GO in coatings due to the many hydrophilic oxygen-containing groups on its surface increases the number of defects in the coating and weakens its physical barrier effect. Although these oxygen-containing groups cause GO agglomeration in coatings, they can still work as suitable active sites to functionalize GO more easily through covalent or non-covalent methods. In fact, many studies report that modified GO can be converted into hydrophobic nanosheets, and the dispersion of GO is remarkably improved in the organic matter [13]. Ruoff et al. [14] revealed that GO that is covalently modified by isocyanate can be stably dispersed in various organic solvents, such as N, N-dimethylformamide (DMF). Besides, Haddon et al. [15] showed that GO modified by octadecylamine (ODA) can be dissolved in organic solvents such as tetrahydrofuran (THF). What is exciting is that Lin et al. found that composite films consisting of GO and ODA can have contact angles of up to $163.2^{\circ}$ [16]. Then, Yun et al. [17] intercalated GO with ethylenediamine, diethylenetriamine, and triethylenetetramine, and found that the longer the molecular chain, the larger the interlayer distance of the modified GO. The modification of GO with octadecylamine can effectively improve the hydrophobicity of GO. Therefore, the functionalized GO has a larger specific surface area through the increase of the interlayer distance and higher compatibility with organic polymers, which is more conducive to improving the corrosion resistance of the coating.

However, there are few studies on composite materials consisting of GO and ODA. It is not known whether such materials can retain the physical properties of their respective components and provide synergistic improvement to the anti-corrosive properties of SMER coatings. Existing related research has mainly focused on the effects of ODA-GO on the mechanical and other physical properties of epoxy resin [18]. Furthermore, GO is a nanoparticle with excellent physical and mechanical properties. Therefore, it is of great significance to study the effect of GO modified by ODA on the corrosion resistance of SMER.

This study aimed to develop a SMER-based nanocomposite coating with enhanced corrosion protection properties by employing modified GO. First, GO was hydrophobically modified by ODA. Then, ODA-GO and SMER were mixed by physical methods to prepare a composite coating. In addition, ODA-GO/SMER were characterized by physical methods, and the corrosion resistance of the ODA-GO/SMER coating was studied by electrochemical impedance spectroscopy (EIS), salt spray testing, and scanning Kelvin probe (SKP). The anticorrosion mechanisms of SMER composite coatings with additions of various amounts of ODA-GO were also studied, providing a basis for the use of ODA-GO/SMER in marine environments.

\section{Experimental}

\subsection{Materials}

Natural graphite was purchased from Qingdao Tengshengda Carbon Machinery Co., Ltd. (Qingdao, China). $\mathrm{H}_{2} \mathrm{SO}_{4}(98 \%), \mathrm{H}_{3} \mathrm{PO}_{4}$, and $\mathrm{HCl}$ were purchased from Pingmei Shenma Group Kaifeng Dongda Chemical Co., Ltd. (Kaifeng, China). $\mathrm{KMnO}_{4}, \mathrm{H}_{2} \mathrm{O}_{2}$ (30\%), ethanol, and DMF were purchased from Sinopharm Chemical Reagent Co., Ltd. (Shanghai, China). Silicone-epoxy resin was purchased from Hubei Sihai Chemical Co., Ltd. (Xiangyang, China) The curing agent was a Silane coupling agent (KH-550) purchased from Nanjing Chengong Silicone Material Co., Ltd. (Nanjing, China).

\subsection{Modification of $G O$ with $O D A$}

A schematic diagram of the preparation of ODA-GO is shown in Figure 1. A preparation of $100 \mathrm{~mL} 0.01 \mathrm{~g} / \mathrm{mL}$ GO (GO was prepared by the Hummers method in the laboratory [19]) DMF dispersion and a $100 \mathrm{~mL} 0.005 \mathrm{~g} / \mathrm{mL}$ ODA absolute ethanol dispersion were mixed and magnetically stirred at $95^{\circ} \mathrm{C}$ in a water bath for $12 \mathrm{~h}$. After the reaction was completed, the product was vacuum filtered and washed with hot absolute ethanol several times to remove unreacted ODA. Then, the product was dried at $40{ }^{\circ} \mathrm{C}$ for $24 \mathrm{~h}$ and ODA-GO was obtained. 


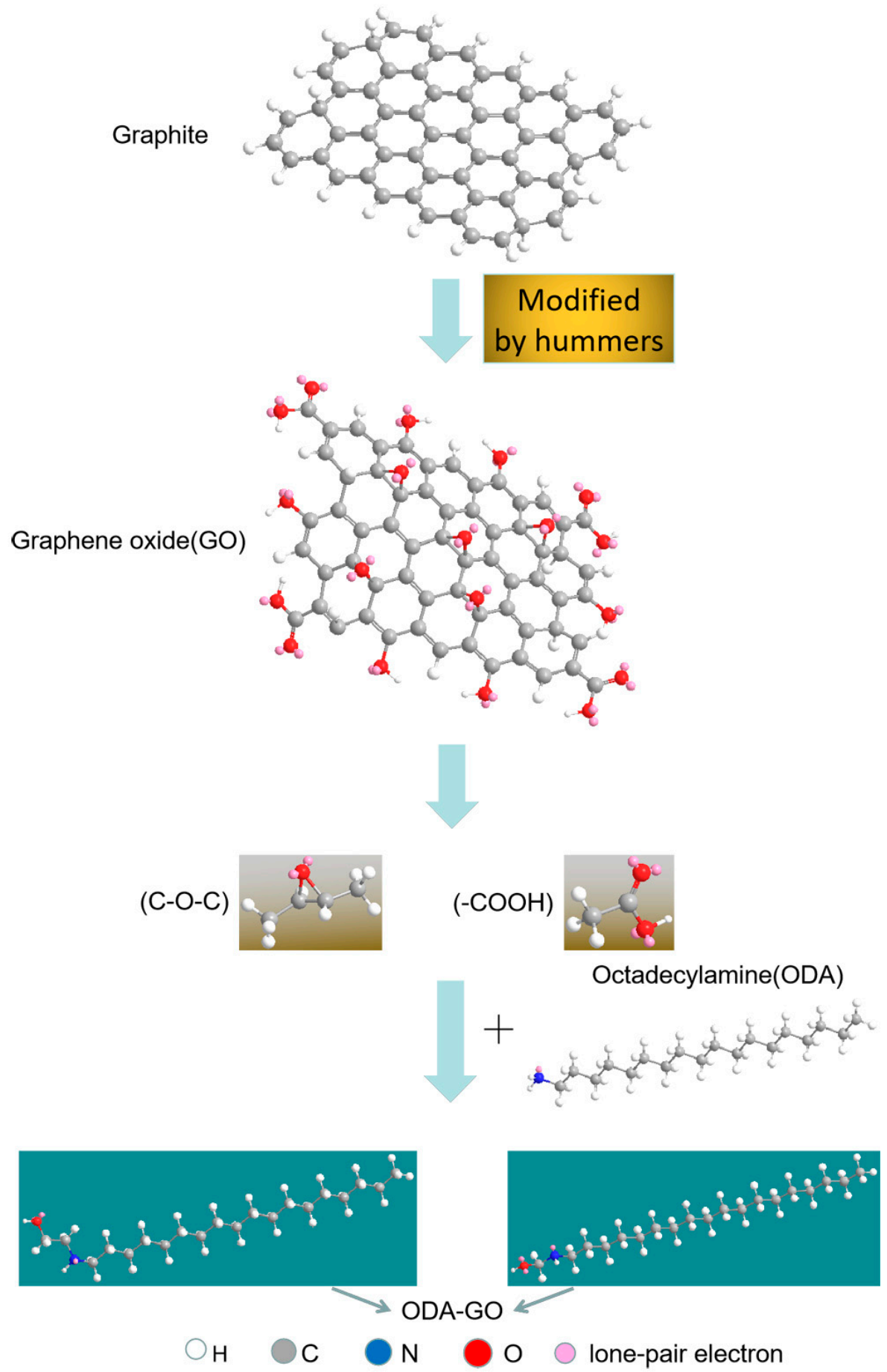

Figure 1. Schematic diagram of the preparation of octadecylamine (ODA)-graphene oxide (GO).

\subsection{Preparation of ODA/SMER Coating}

The steel sample used in this study was made of Q235 carbon steel. First of all, the steel samples were ground with 240 grit abrasive $\mathrm{SiC}$ paper, degreased by acetone, rinsed with deionized water, and dried under airflow.

To prepare ODA-GO/SMER and the other composite coatings, we first weighed a certain amount of homemade GO and ODA-GO to ensure that the content of GO in the coating was $2 \mathrm{wt} . \%$ and the ODA-GO contents were $0.5 \mathrm{wt} . \%, 1 \mathrm{wt} . \%$ or $2 \mathrm{wt} . \%$. Then, the GO and ODA-GO were separately dispersed in DMF to obtain a suspension with a concentration of $1 \mathrm{mg} / \mathrm{mL}$, which was then separately ultrasonically dispersed $(120 \mathrm{~W}$, 
$30 \mathrm{~min}$ ) and vacuum filtered to obtain wet GO and ODA-GO. Then, the wet nanosheets were added into the SMER and the composite coatings were magnetically stirred at $120 \mathrm{~W}$ for $30 \mathrm{~min}$. Furthermore, a curing agent was added to the composite coatings at an SMER: curing agent ratio of 5:1 $(w / w)$, and the prepared composite coatings were mechanically stirred for $5 \mathrm{~min}$. Then, the composite coatings were degassed in a vacuum chamber for $10 \mathrm{~min}$ and coated on the steel samples prepared previously. Finally, the coatings were cured at room temperature $\left(25 \pm 2{ }^{\circ} \mathrm{C}\right)$. The thicknesses of the dry coating films were measured as $200 \pm 10 \mu \mathrm{m}$ by a MiniTest 3100 tester (EPK, Germany). A schematic diagram of the preparation of the ODA-GO/SMER coating is shown in Figure 2.

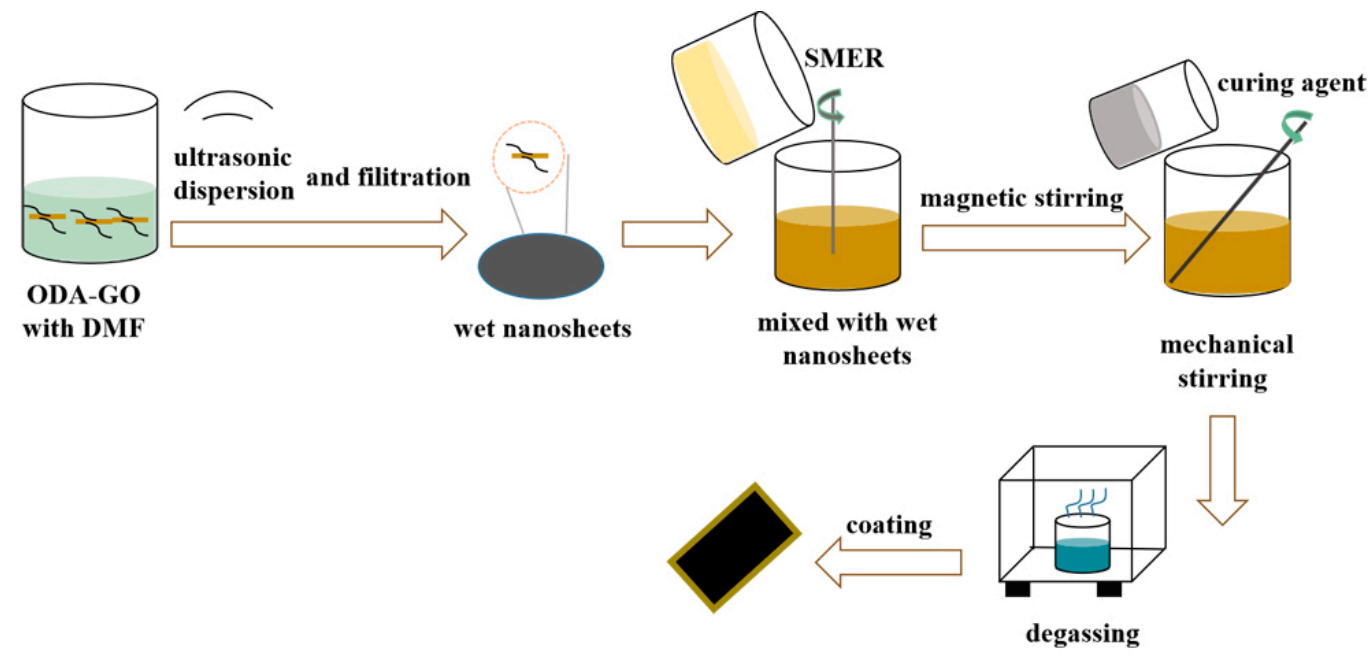

Figure 2. Schematic diagram of the preparation of ODA-GO/silicone-modified epoxy resin (SMER) coatings.

\subsection{Characterization and Measurement}

\subsubsection{Characterization of ODA-GO Nanosheets and ODA-GO SMER Coating}

The phase crystalline structures of the functional GO nanosheets were characterized by X-ray diffraction analysis (XRD) (Philips X Pert Pro, PANalytical, Almelo, Netherlands) within the range of $1 \sim 50^{\circ}(2 \theta)$ with a $\mathrm{Cu} \mathrm{K} \alpha$ radiation source. Fourier transform infrared spectroscopy (FT-IR) spectra were recorded at $4000 \sim 400 \mathrm{~cm}^{-1}$ with an FT-IR spectrometer (Perkin-Elmer, Waltham, MA, USA) at room temperature. Raman spectra were measured with an optical maser with a wavelength of $780 \mathrm{~nm}$ and power of $24 \mathrm{~mW}$ by a Raman spectrometer (Thermal DXR, ThermoFisher, Waltham, MA, USA). X-ray photoelectron spectroscopy (XPS) spectra were recorded by a Specs EA 10 Plus with an Al $\mathrm{K}_{\alpha}$ radiation source at a pressure of $10^{-9}$ mbar after Ar-ion bombardment.

A field-emission scanning electron microscopy (FE-SEM) (Nava 400 NanoSEM, FEI, Hillsboro, OR, USA) equipped with energy disperse spectroscopy (EDS, Oxford, Oxford, UK) was used to investigate the surface morphology of the ODA-GO and the cross-sectional morphology of the composite SMER coatings. The hydrophobicity of the SMER composite coatings was tested by a contact angle measuring system (OCA15PRO, DATAPHYSI, Filderstadt, Germany) at $25 \pm 2{ }^{\circ} \mathrm{C}$. A water absorption test of the SMER composite coatings ( $200 \pm 10 \mu \mathrm{m}$ in thickness) was carried out according to ASTM D570.

In addition, the water absorption was measured as:

$$
T_{w}=\frac{m_{t}-m_{0}}{m_{0}} \times 100 \%
$$

where $m_{0}$ and $m_{t}$ are the masses of the coatings before and after immersion in deionized water, respectively, and $t$ is the immersion time. The coated samples were immersed in deionized water for 12 days and their masses were measured at intervals of $24 \mathrm{~h}$. 


\subsubsection{Salt Spray Test}

The corrosion resistance of the coated steels (dimensions $5 \mathrm{~mm} \times 70 \mathrm{~mm} \times 150 \mathrm{~mm}$ ) was investigated by salt spray tests in a Q-FOG Cyclic Corrosion Tester (Q-Lab, Westlake, $\mathrm{OH}, \mathrm{USA}$ ) according to the ASTM B117-09 standard. The coated steels were scratched and then exposed to a $5 \mathrm{wt} . \% \mathrm{NaCl}$ fog $(\mathrm{pH} 6.5 \sim 7.2)$ at a constant temperature of $35^{\circ} \mathrm{C}$ for $720 \mathrm{~h}$.

\subsubsection{Electrochemical Measurements}

Electrochemical measurements of the composite coatings were made by electrochemical impedance spectroscopy (EIS) using an Autolab PGSTAT302F electrochemical workstation on a three-electrode cell. The coated steel, a saturated calomel electrode (SCE), and a platinum sheet were used as the working electrode, reference electrode, and counter electrode, respectively. After the coated steels were immersed in $3.5 \mathrm{wt} . \% \mathrm{NaCl}$ solution for different times $(1,3,7,14$, and 28 days), EIS tests were conducted with a potential disturbance of $\pm 10 \mathrm{mV}$ in the frequency range of $10^{-2}$ to $10^{5} \mathrm{~Hz}$. All EIS tests were performed at the open-circuit potential (OCP) of the coated steels.

A VersaSCAN scanning Kelvin probe system (SKP; Princeton, NJ, USA) was used to measure the Volta potential distribution on the different coated samples with artificial scratches $(0.25 \mathrm{~mm}$ in width and $10 \mathrm{~mm}$ in length). A tungsten filament microelectrode with $250 \mu \mathrm{m}$ diameter was used. Before measurement, the coated samples were immersed in $3.5 \mathrm{wt} . \% \mathrm{NaCl}$ solution for a certain time period, then taken out of the solution, rinsed with distilled water for $5 \mathrm{~s}$, and dried in high-purity nitrogen (99.999\%). Then, SKP measurements were conducted with a 1428-point mesh across the coated sample surfaces at room temperature (about $25^{\circ} \mathrm{C}$ ).

\section{Results and Discussion}

\subsection{Characterization of ODA-GO Nanosheets}

Figure 3 shows the XRD spectra, FTIR spectra, and Raman spectra of GO and ODAGO. It can be seen from the XRD patterns (Figure 3a) that the GO sheets at $10.18^{\circ}$ with the d-spacing of $8.68 \AA$ indicate the complete oxidation of graphite [20]. The diffraction peak of ODA-GO is observed at $7.59^{\circ}$ with the d-spacing of $11.62 \AA$. The significant increase of d-spacing in ODA-GO compared to GO can be ascribed to the ODA chains present between the intergalleries of the GO sheets because of the covalent bonding of ODA with the GO surface and almost vertical configuration of ODA on the surface of ODA-GO [2]. In addition, a broad and low characteristic diffraction peak appeared at around $22^{\circ}$ at $2 \theta$ in the XRD spectra of the ODA-GO, which is close to the characteristic diffraction peak of natural graphite $\left(26^{\circ}\right)$. This can be attributed to the reduction of the oxygen-containing groups in GO by the amine groups in ODA.

Figure $3 \mathrm{~b}$ shows the FT-IR spectra of GO and ODA-GO. Characteristic vibration absorption peaks of oxygen-containing functional groups, such as $\mathrm{O}-\mathrm{H}$ bonds at $3427 \mathrm{~cm}^{-1}$, $\mathrm{C}=\mathrm{O}$ bonds at $1727 \mathrm{~cm}^{-1}$, and $\mathrm{C}-\mathrm{O}-\mathrm{C}$ bonds at $1052 \mathrm{~cm}^{-1}$, can be clearly observed in the GO FT-IR spectrum. In the ODA-GO FT-IR spectrum, the appearance of new vibration absorption peaks characteristic of N-H bonds at $1571 \mathrm{~cm}^{-1}$ and C-N bonds at $1210 \mathrm{~cm}^{-1}$ and the decline in the intensity of peaks of $\mathrm{C}-\mathrm{O}-\mathrm{C}$ bonds at $1052 \mathrm{~cm}^{-1}$ and $\mathrm{C}=\mathrm{O}$ bonds at $1727 \mathrm{~cm}^{-1}$ indicate that there was a chemical reaction between the oxygen-containing functional groups of the GO nanosheets and the amine groups of ODA $[2,6,12]$.

Figure $3 c$ shows the Raman spectra of GO and ODA-GO. GO exhibits the G band at $1646 \mathrm{~cm}^{-1}$ and D band at $1396 \mathrm{~cm}^{-1}$, respectively [21]. After modification with ODA, the $\mathrm{D}$ band shifts from $1396 \mathrm{~cm}^{-1}$ to $1417 \mathrm{~cm}^{-1}$. The $\mathrm{I}_{\mathrm{D}} / \mathrm{I}_{\mathrm{G}}$ ratio, which characterizes the crystal structural integrity of the ODA-GO composites was higher than that of GO, present a slight increase from 1.36 for GO to 1.40 for ODA-GO, indicating that no more defects are introduced after the modification of GO with ODA and the GO preserves its basic structural properties $[22,23]$. 

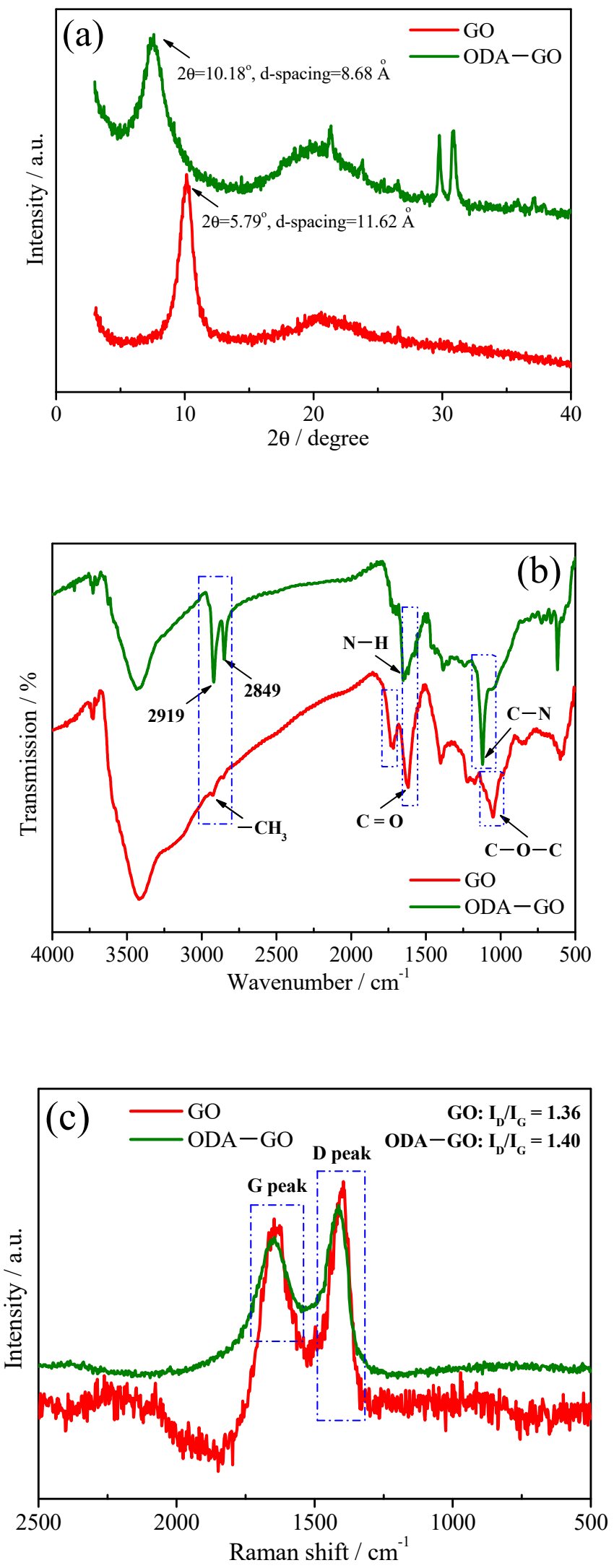

Figure 3. XRD spectra (a), FT-IR spectra (b), and Raman spectra (c) of GO and ODA-GO. 
The XPS results for GO and ODA-GO are shown in Figure 4. Compared with the full XPS spectrum of GO, the appearance of N1s in the full XPS spectrum of ODA-GO (Figure 4a) demonstrates that the presence of GO functionalized with ODA on the sample surface [2]. Furthermore, the addition of C-N located at $285.1 \mathrm{eV}$ and the disappearance of $\mathrm{C}=\mathrm{O}$ located at $288.3 \mathrm{eV}[7,24]$ in the high-resolution spectra of ODA-GO (Figure 4c) compared with those of GO (Figure $4 \mathrm{~b}$ ) indicate that oxygen-containing groups in the GO nanosheets were chemically reduced by amine groups in ODA, and then ODA was successfully grafted onto the surface of GO.
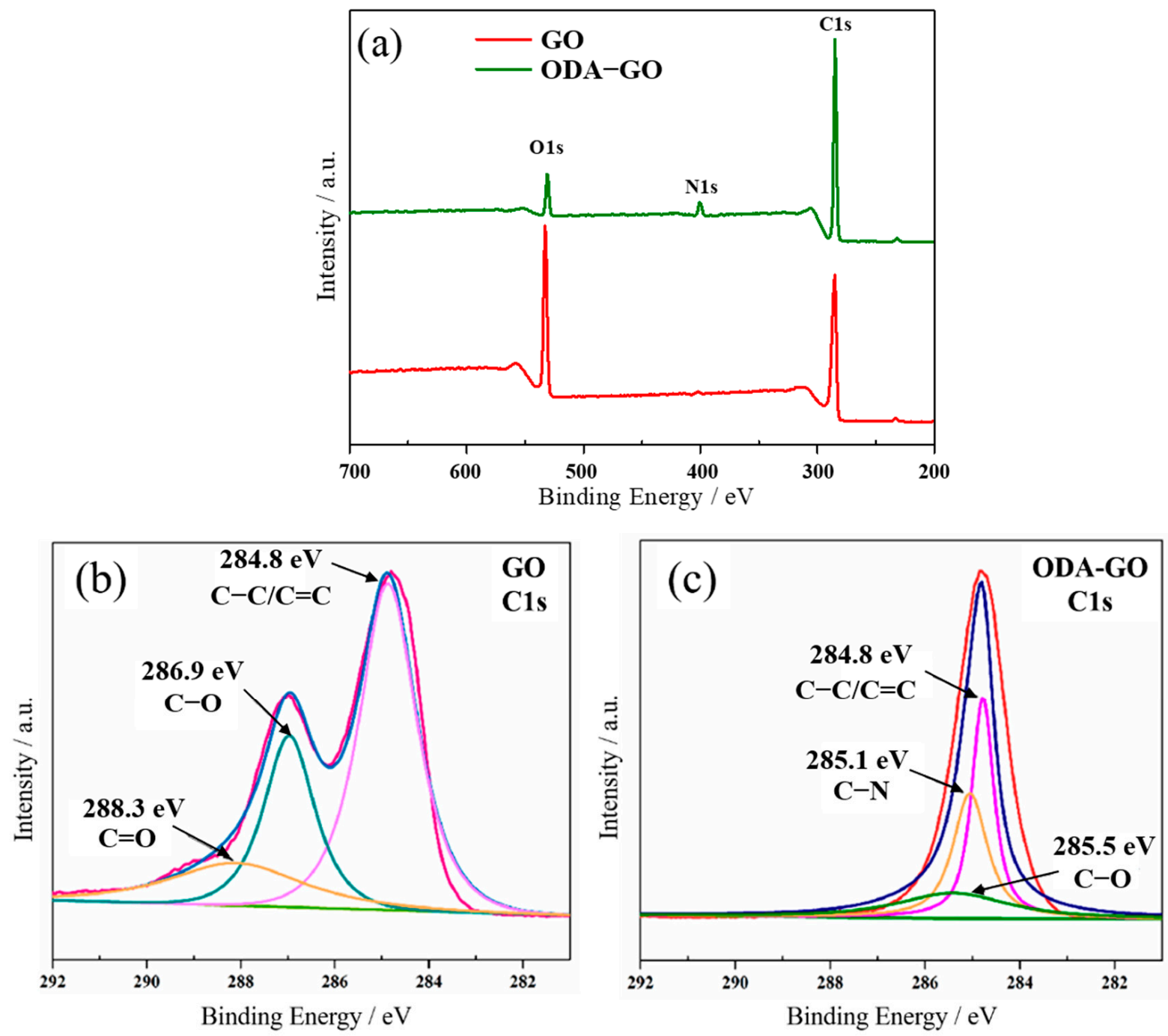

Figure 4. XPS survey spectrum (a) and high-resolution spectra of (b) C1s for GO and (c) C1s for ODA-GO.

\subsection{Physical Performance Measurements of the ODA-GO Nanosheets}

Figure 5 shows the surface observation of GO and ODA-GO at different magnifications. There were many wrinkles on the surface of GO, which were produced by the oxidation of graphite by strong oxidants (Figure 5a,b). However, the surface of ODA-GO was smoother than that of GO and some acicular nanoparticles on the ODA-GO surface can be observed. Generally speaking, a rougher surface possesses better hydrophobicity. Hydrophobic ODA, however, dominated the hydrophobicity of ODA-GO rather than the surface roughness. 

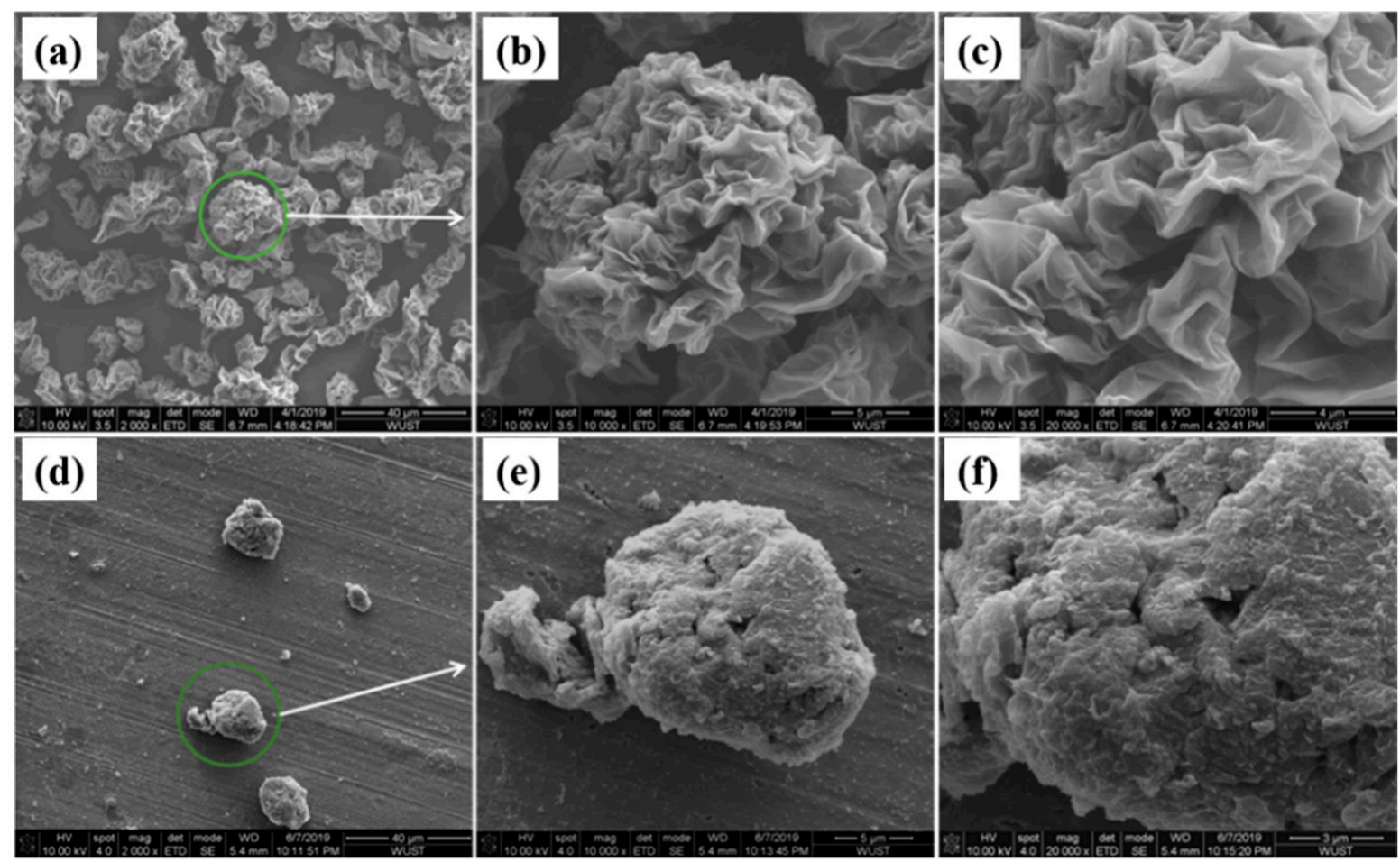

Figure 5. Surface observation of GO (a-c) and ODA-GO (d-f).

Contact angle tests were performed on the film surfaces of GO and ODA-GO (Figure 6). The contact angle of ODA-GO was $50^{\circ}$ greater than that of GO, which indicates that GO had been converted into hydrophobic nanosheets after modification by ODA. The higher the roughness of the micromorphology of the materials, the higher their hydrophobicity [25]. Therefore, the roughness of ODA-GO was greater than that of GO due to a large number of long-chain alkyl functional groups being grafted onto the GO surfaces.
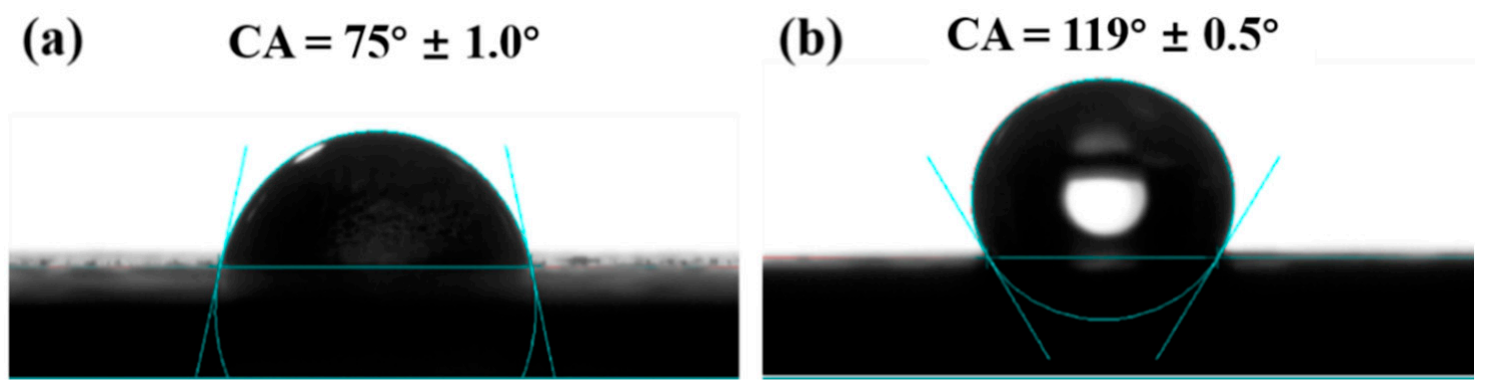

Figure 6. Contact angle of GO (a) and ODA-GO (b).

Consequently, in order to verify that ODA-GO has higher hydrophobicity than GO, ODA-GO and GO were dissolved in deionized water, absolute ethanol, and DMF, respectively, and dispersed ultrasonically for $30 \mathrm{~min}$. Then, all the suspensions were left to stand for $24 \mathrm{~h}$. Images of the sedimentation tests of GO and ODA-GO are shown in Figure 7. The dispersion of GO was better in water than in absolute ethanol or DMF. However, the dispersion of GO modified by ODA was worst in water. These results demonstrate the GO modified by ODA has high hydrophobicity. In addition, the sedimentation test results are consistent with those of the contact angle tests. 


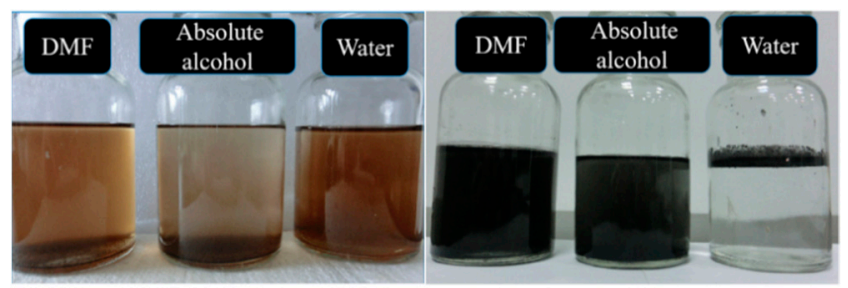

(a)

(b)

Figure 7. Observation of dispersion for GO (a) and ODA-GO (b).

\subsection{Interfacial Adhesion Properties of ODA-GO/SMER Coatings}

Figure 8 shows the microstructure of cross-section and component analysis of the magnified area of five coatings. $\mathrm{C}, \mathrm{O}$, and $\mathrm{N}$ elements aggregated in the three ODA-GO/SMER coatings, but not $\mathrm{Si}$. Combined with the other characterization results (Figures 3 and 4 ), which illustrated that the nanoparticles in the specific regions would be ODA-GO. At the same time, in the pure SMER coating, C, N, O, and Si elements were evenly distributed (Figure 8f). Besides, there was only an enrichment of $C$ and $O$ elements in the GO/SMER coating (Figure 8g), which infers that the nanoparticles in the specific regions were GO, and GO aggregated in the SMER due to a large number of hydrophilic oxygen-containing functional groups on its surface (Figures 3 and 4). Thus, the size of GO nanoparticles (Figure $8 \mathrm{~g}$ ) was greater than that of ODA-GO in the $0.5 \mathrm{wt} . \%$ and $1 \mathrm{wt} . \%$ ODA-GO/SMER preparations (Figure $8 \mathrm{~h}, \mathrm{i}$ ). Furthermore, with increases in the content of ODA-GO in the SMER coating, the size of the nanoparticles increased (Figure $8 \mathrm{~h}-\mathrm{j}$ ), indicating that the hydrophobic ODA-GO (Figures 6 and 7) was well dispersed in the organic coating; however, when the content of ODA-GO in the SMER coating reached $2 \mathrm{wt} . \%$, agglomeration could occur (Figure 8j).

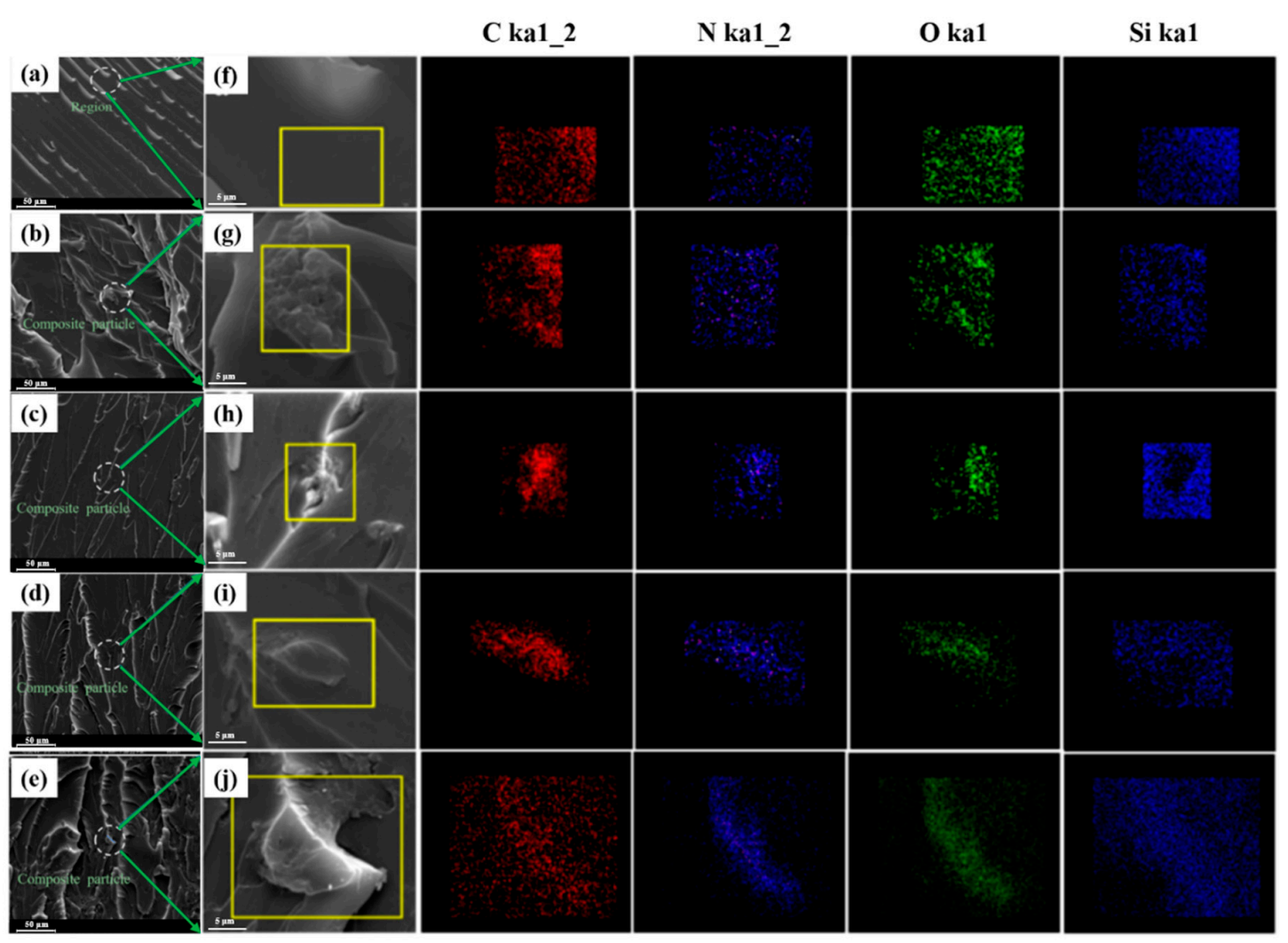

Figure 8. Microstructure observation of cross-section and component analysis of magnified area for SMER (a,f) GO/SMER (b,g), 0.5 wt.\% (c,h), 1 wt.\% (d,i) and 2 wt.\% (e,j) ODA-GO/SMER. 
It can be seen that the interfacial adhesion of the $1 \mathrm{wt} . \%$ ODA-GO/SMER coating was the highest and that the ODA-GO possessed good compatibility in $1 \mathrm{wt}$ \% ODA-GO/SMER. This was due to the reduction of the oxygen-containing groups on the surface of GO by ODA, which made it easier to be dispersed in the organic polymer matrix. On the one hand, when the addition of ODA-GO in the SMER coating was $0.5 \mathrm{wt} \%$, although ODA-GO could be well dispersed in the coating, it did not completely fill the defects in the SMER coating. On the other hand, with the addition of 2 wt.\% ODA-GO in the SMER coating, it would agglomerate and lower the coating's interfacial adhesion. Therefore, the addition of 1 wt.\% ODA-GO can effectively fill the defects in a SMER coating and ensure high compatibility and high interfacial adhesion between nanosheets and coatings.

\subsection{Hydrophobicity and Water Absorption Properties of the ODA-GO/SMER Coating}

Figure 9 shows the contact angle values for the five different coatings. All coatings were hydrophobic due to their contact angle values larger than $90^{\circ}$. It can be seen from Figure $9 a, b$ that the contact angle values of the pure SMER, GO/SMER, and ODAGO/SMER composite coatings were very close, indicating that the hydrophobicity of the SMER did not change significantly after the addition of GO and ODA-GO. All five composite coatings had good hydrophobicity.
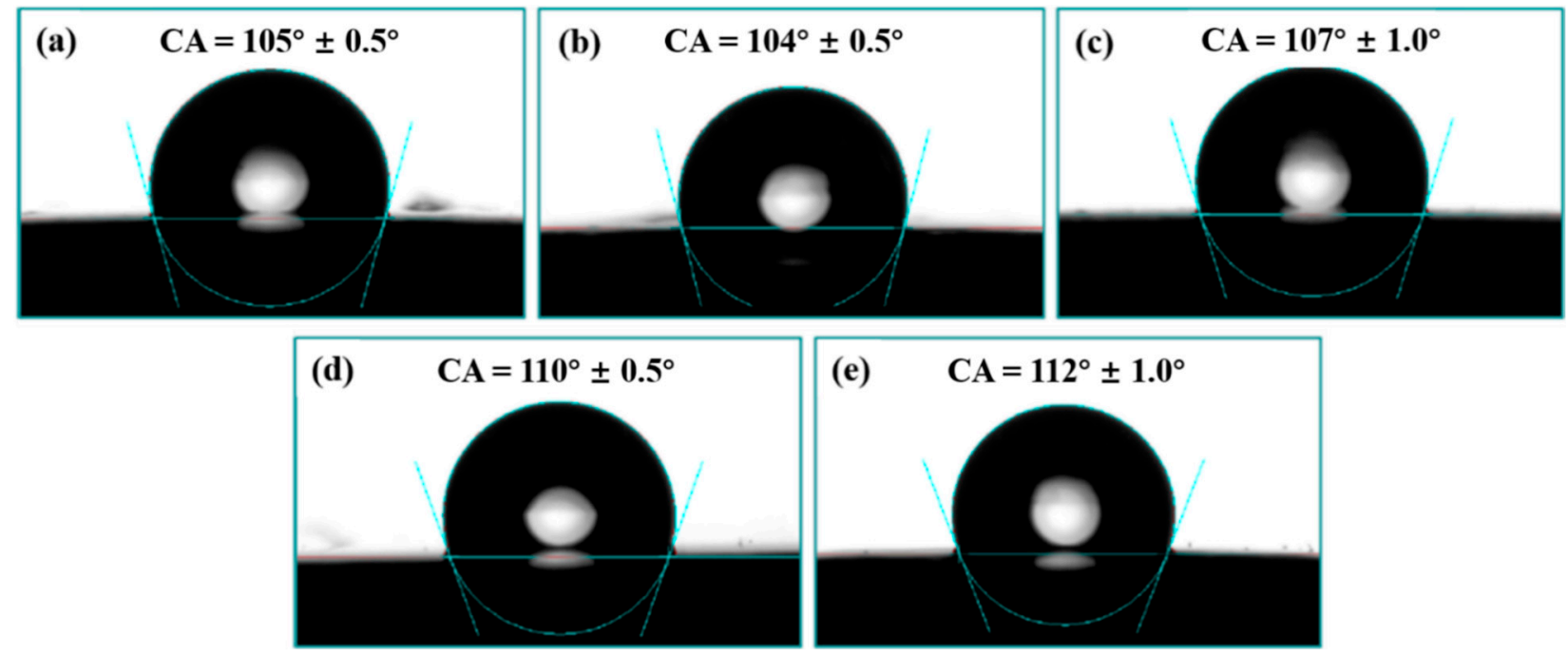

Figure 9. Contact angle of SEMR (a), GO/SMER (b), 0.5 wt.\% (c), 1 wt.\% (d) and 2 wt.\% (e) ODA-GO/SMER.

Figure 10 shows the water absorption time-dependence of the five organic coatings. When soaking began, the water absorption of the pure SMER and GO/SMER coatings was high due to many defects existing in the coatings. In the ODA-GO/SMER coatings, however, the water absorption was lower than that of the other two coatings due to its good dispersion in the organic polymer matrix caused by the hydrophobic functional groups on the ODA-GO surface. When the addition of ODA-GO in SMER was less than $0.5 \mathrm{wt} . \%$, most defects in the coating were not effectively filled. As the additive amount of ODA-GO in SMER increased to $1.0 \mathrm{wt}$ \%, the defects in SMER coatings can be effectively filled without agglomeration of ODA-GO. When the additive amount of ODA-GO in SMER reached $2.0 \mathrm{wt}$ \%, agglomeration of ODA-GO occurred in SMER coating and the water absorption increased again. Therefore, $1 \mathrm{wt} \%$ ODA-GO/SMER coating has the lowest amount of water absorption. 


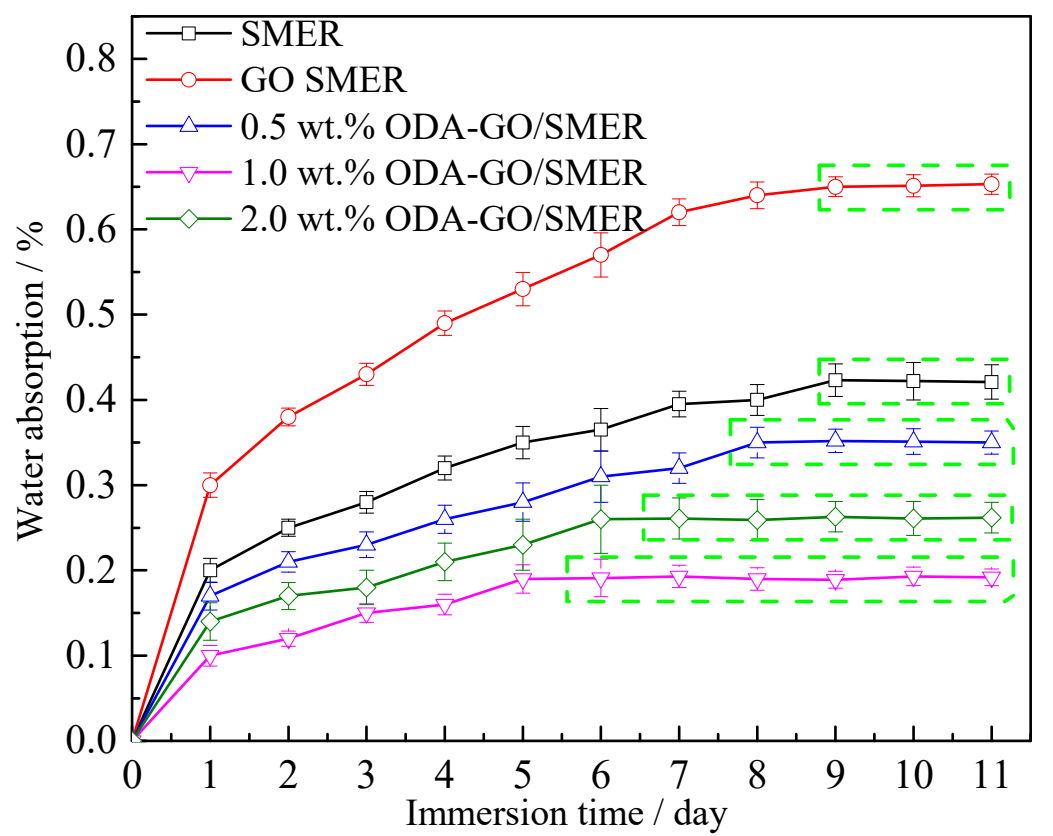

Figure 10. Water absorption of SEMR, GO/SMER, 0.5 wt. $\%, 1$ wt. $\%$, and 2 wt. $\%$ ODA-GO/SMER.

\subsection{Effect of ODA-GO on SMER Coating Corrosion Resistance}

Figure 11 shows macroscopic topographic photos of the pure SMER, GO/SMER, $0.5 \mathrm{wt} . \%$ ODA-GO/SMER, $1 \mathrm{wt} . \%$ ODA-GO/SMER, and $2 \mathrm{wt} . \%$ ODA-GO/SMER coated samples at different salt spray times. Pure SMER and GO/SMER exhibited blistering at $200 \mathrm{~h}$. With further exposure time, the blistering and corrosion products of pure SMER and GO/SMER increased. The ODA-GO/SMER-coated samples were also exposed to salt spray testing. Although the corrosion products near the scratches in the $1 \mathrm{wt} . \%$ and $2 \mathrm{wt} . \%$ ODA-GO/SMER samples increased with exposure time, those of the $1 \mathrm{wt} . \%$ and $2 \mathrm{wt} . \%$ ODA-GO/SMER samples did not blister after $720 \mathrm{~h}$ exposure to salt spray. After exposure to salt spray for the same time, the amount of corrosion products in the $1 \mathrm{wt} . \%$ ODA-GO/SMER sample was less than that in the $2 \mathrm{wt} . \%$ ODA-GO/SMER. In the $0.5 \mathrm{wt} . \%$ ODA-GO/SMER-coated sample, not only did corrosion products appear near the scratches but blistering was also observed after $720 \mathrm{~h}$ exposure to salt spray. Based on the above results, the corrosion resistance of the five different types of coatings was comprehensively evaluated. The anti-corrosion performance of ODA-GO/SMER coatings was better than that of pure SMER and GO/SMER coatings. Among the three ODA-GO/SMER coatings, the anti-corrosion effect of the $1 \mathrm{wt} . \%$ ODA-GO/SMER coating was better than that of the $0.5 \mathrm{wt} . \%$ and $2 \mathrm{wt} . \%$ ODA-GO/SMER coatings. This indicates that as the amount of ODA-GO added to the SMER coating increases, its corrosion resistance increases and then declines, with the optimum amount of ODA-GO in SMER being $1 \mathrm{wt} . \%$.

Figures 12 and 13 show the Bode plots and low-frequency end resistance statistics (Z) of EIS for the five coated samples in $3.5 \mathrm{wt}$. $\% \mathrm{NaCl}$ solution at different times. The equivalent electrical circuit is shown in Figure 12, where $R_{\mathrm{S}}$ is the solution resistance, i.e., the resistance between the working and reference electrodes. $R_{\mathrm{c}}$ and $C P E_{\mathrm{c}}$ are the coating resistance and the non-ideal capacitance of coating, $R_{\mathrm{ct}}$ is the charge transfer resistance and $C P E_{\mathrm{dl}}$ is the non-ideal capacitance of double layer. It can be seen from the figures that as the immersion time increases, the low-frequency end impedance values and the high-frequency phase angles of the various coated samples continuously decrease, indicating that the corrosive medium gradually permeates into the coatings. After 28 days of soaking in $3.5 \mathrm{wt} . \% \mathrm{NaCl}$ solution, the low-frequency end impedance of the GO/SMERcoated sample dropped below $10^{5} \Omega \cdot \mathrm{cm}^{2}$, which means that its physical barrier property is poor. The low-frequency end impedance of the pure SMER sample also dropped to about $1.0 \times 10^{5} \Omega \cdot \mathrm{cm}^{2}$, indicating that it had a certain physical barrier property. Compared 
with the three ODA-GO/SMER-coated samples, the low-frequency end resistance value of $0.5 \mathrm{wt} . \%$ ODA-GO/SMER-coated sample was about $4.2 \times 10^{6} \Omega \cdot \mathrm{cm}^{2}$ in the early stage of soaking and decreased to $7.8 \times 10^{5} \Omega \cdot \mathrm{cm}^{2}$ after 28 days of immersion. For the $2 \mathrm{wt} \%$ ODA-GO/SMER sample, the low-frequency end impedance value was $1.72 \times 10^{8} \Omega \cdot \mathrm{cm}^{2}$ at the early stage of soaking and decreased to $5.6 \times 10^{6} \Omega \cdot \mathrm{cm}^{2}$ after 28 days of soaking. The low-frequency end impedance of the $1 \mathrm{wt} . \%$ ODA-GO/SMER sample maintained a high value during the immersion experiment. The low-frequency end impedance value of the $1 \mathrm{wt} . \%$ ODA-GO/SMER sample was $6.2 \times 10^{8} \Omega \cdot \mathrm{cm}^{2}$ on the first day and was about $10^{8} \Omega \cdot \mathrm{cm}^{2}$ on the 28th day. Hence, the coating effectively delayed the permeation of the corrosive medium into the steel matrix and provided good protection. According to the above results, the anti-corrosion performance of the ODA-GO/SMER coatings was better than that of the GO/SMER and pure SMER coatings. The physical barrier effect of the ODA-GO/SMER coatings increased with the amount of ODA-GO added to the SMER. The anti-corrosion performance of the organic coating was best with $1 \mathrm{wt} . \%$ ODA-GO in the SMER.

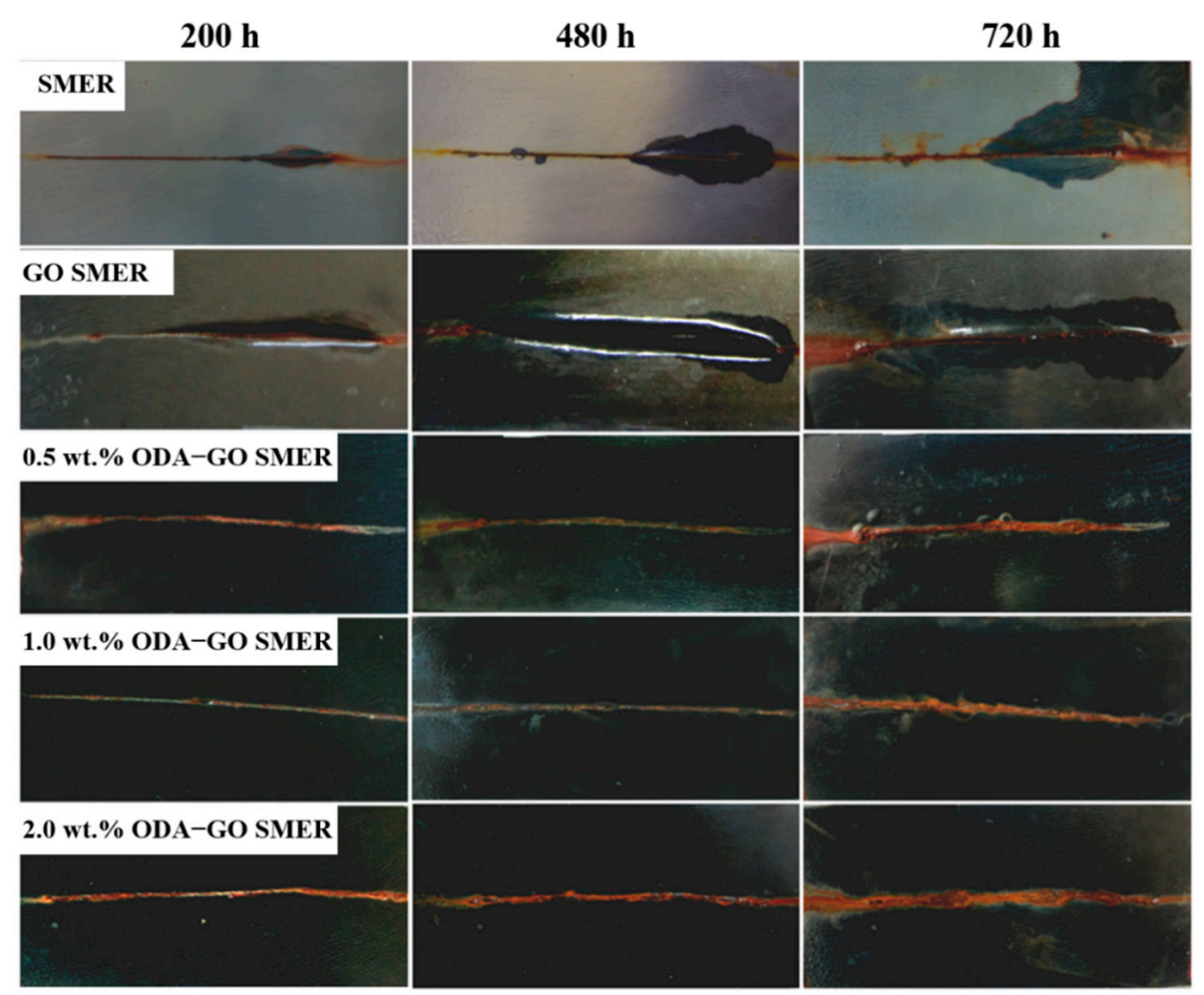

Figure 11. The appearance of SEMR, GO/SMER, 0.5 wt. $\%, 1$ wt. $\%$, and 2 wt. $\%$ ODA-GO/SMER coatings after $200 \mathrm{~h}, 480 \mathrm{~h}$, and $720 \mathrm{~h}$ exposure to salt spray. 

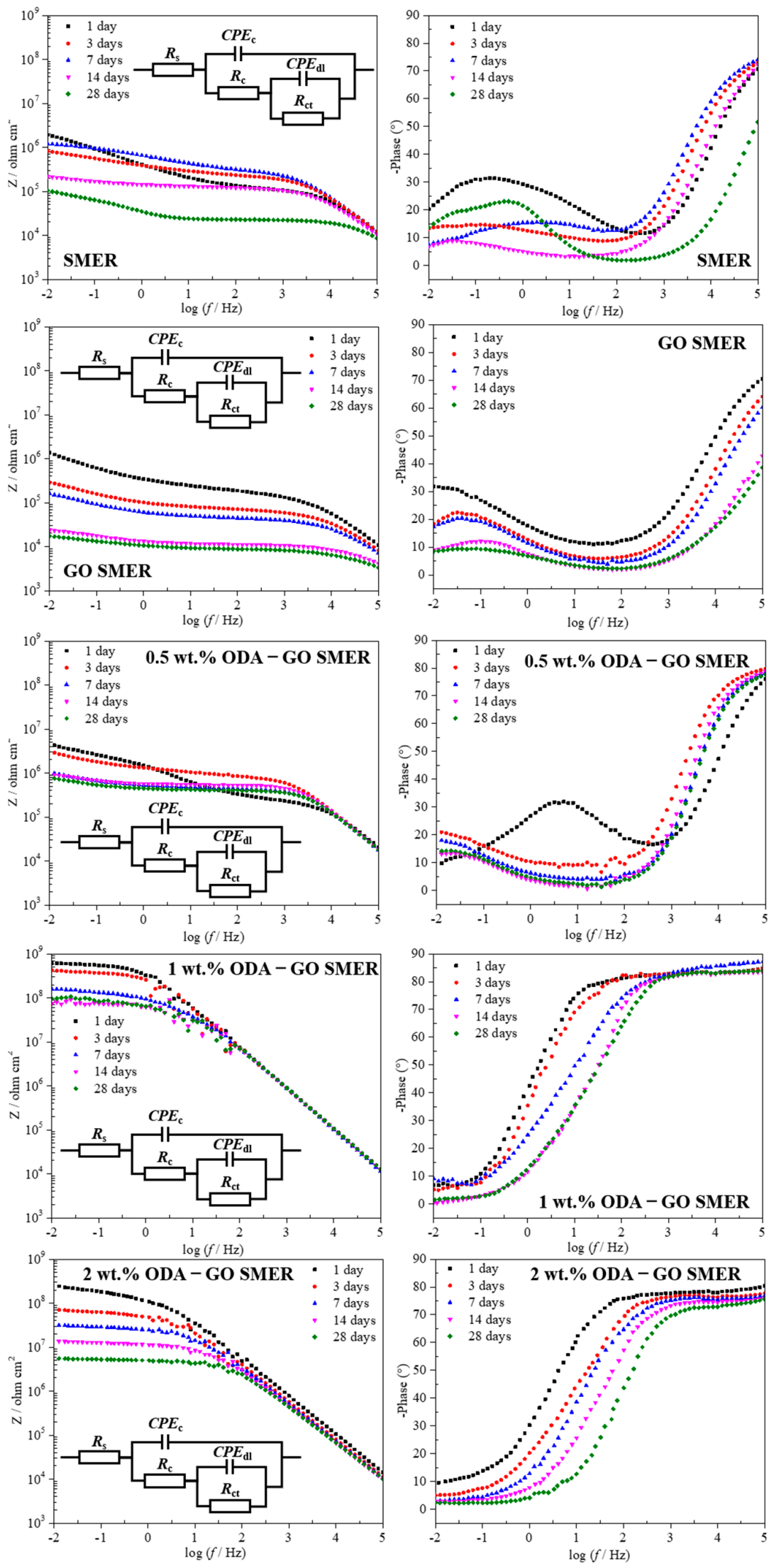

Figure 12. Bode plots for SEMR, GO/SMER, $0.5 \mathrm{wt} . \%, 1 \mathrm{wt} . \%$, and $2 \mathrm{wt} . \%$ ODA-GO/SMER coatings applied on the steel surface after immersion in $3.5 \mathrm{wt} . \% \mathrm{NaCl}$ solution for different times. 


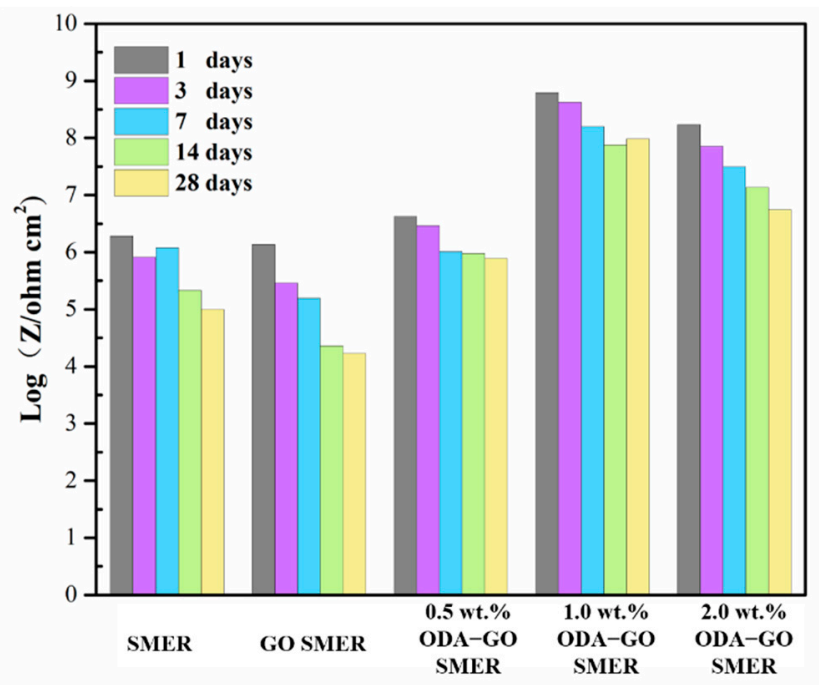

Figure 13. Resistance statistics at $10^{-2} \mathrm{~Hz}$ of electrochemical impedance spectroscopy (EIS) results for different coatings after immersed in $3.5 \mathrm{wt} . \% \mathrm{NaCl}$ solution at different times.

\subsection{Cathodic Anti-Peeling Performance of the ODA-GO/SMER Composite Coatings}

Scanning Kelvin probe (SKP) tests were performed on the SMER-, GO/SMER-, and $1 \mathrm{wt} . \% \mathrm{ODA}-\mathrm{GO} / \mathrm{SMER}$-coated steel samples after immersion in $3.5 \mathrm{wt} . \% \mathrm{NaCl}$ solution for various times at the artificially defective Volta potential. The results are shown in Figure 14. The SKP is a non-contact and non-destructive technology. There is a linear relationship between the measured Volta potential and the corrosion potential between metals. In the same measurement system, a lower Volta potential corresponds to the anode, and a higher Volta potential corresponds to the cathode. As the coating is immersed in $3.5 \mathrm{wt} . \% \mathrm{NaCl}$ solution for an extended period of time, the potential boundary between the complete coating and defective coating will move to the coating side. According to the displacement of its potential boundary, the anti-cathode peeling performance of the coating can be evaluated [26]. Therefore, SKP is widely used to measure degradation processes at the interface between a coating and a metal substrate, including coating peeling, anodic dissolution of the metal substrate, and formation of corrosion products.

After artificial defects were scratched onto the surfaces of the three coated steel plates, they were immersed in $3.5 \mathrm{wt} . \% \mathrm{NaCl}$ solution. Due to the influence of corrosive media, such as water and oxygen, slow corrosion will occur at the defects. At this time, the coating defects serve as anodes and the complete coating areas serve as cathodes. The reactions occur as follows:

(1) Anodic reaction: $\mathrm{Fe}-2 \mathrm{e} \rightarrow \mathrm{Fe}^{2+}$

(2) Cathodic reaction: $\mathrm{O}_{2}+2 \mathrm{H}_{2} \mathrm{O}+4 \mathrm{e} \rightarrow 4 \mathrm{OH}^{-}$

(3) Secondary corrosion reaction: $\mathrm{Fe}+2 \mathrm{OH}^{-} \rightarrow \mathrm{Fe}(\mathrm{OH})_{2} \mathrm{The} \mathrm{Fe}(\mathrm{OH})_{2}$ formed at the steel matrix is easily oxidized to $\mathrm{Fe}_{2} \mathrm{O}_{3}$ and $\mathrm{FeOOH}$.

(4) $2 \mathrm{Fe}(\mathrm{OH})_{2}+1 / 2 \mathrm{O}_{2} \rightarrow 2 \mathrm{FeOOH}+\mathrm{H}_{2} \mathrm{O}$

(5) $4 \mathrm{Fe}(\mathrm{OH})_{2}+\mathrm{O}_{2} \rightarrow 2 \mathrm{Fe}_{2} \mathrm{O}_{3}+4 \mathrm{H}_{2} \mathrm{O}$

When the three different coatings applied on the steel samples were soaked in $3.5 \mathrm{wt} . \%$ $\mathrm{NaCl}$ solution for $24 \mathrm{~h}$, they were taken out and dried under airflow, and the defects were found to be covered by large amounts of rust. When the Volta potential map of the local defects in the coatings was measured in air, it was found that the potential distribution was reversed. The local defects with high potential serve as cathode areas, and the complete coating areas serve as anode areas. This may be due to the large potential difference between complete and defective coatings [27], which causes a coupling effect. When the $\mathrm{FeOOH}$ rust covering a defect contacts the steel substrate underneath a complete coating area, $\mathrm{FeOOH}$ acts as a cathodic reactant and is reduced to $\mathrm{Fe}_{3} \mathrm{O}_{4}$, which also stimulates the formation of new anodes under the coating. Therefore, the defects covered by $\mathrm{Fe}_{3} \mathrm{O}_{4}$ serve 
as cathode areas and the steel substrate close to the potential boundary under the complete coating area will occur anodic dissolution. The reaction occurs as follows:

(6) Anodic reaction: $\mathrm{Fe}-2 \mathrm{e} \rightarrow \mathrm{Fe}^{2+}$

(7) Cathodic reaction: $8 \mathrm{FeOOH}+\mathrm{Fe}^{2+} 2 \mathrm{e} \rightarrow 3 \mathrm{Fe}_{3} \mathrm{O}_{4}+4 \mathrm{H}_{2} \mathrm{O}$

$24 \mathrm{~h}$ SMER

Figure 14. Scanning Kelvin probe (SKP) potential measurements in air for SEMR, GO/SMER, and 1 wt.\%.

After extended immersion times of $48 \mathrm{~h}$ and $96 \mathrm{~h}$, the coated steel was taken out and air-dried. The reaction between the coating defects and the complete coating was the same as that at $24 \mathrm{~h}$ in air. SKP tests were performed on the three coated steel plates in air. By observing the SKP potential diagrams of the three coatings at $24 \mathrm{~h}, 48 \mathrm{~h}$, and $96 \mathrm{~h}$, and by comparing the displacements of their potential boundaries, it was found that the anti-peeling performance of the $1 \mathrm{wt}$.\% ODA-GO/SMER coating was better than those of the GO/SMER coating and SMER coating. It is known that the higher the anti-peeling performance between a coating and steel substrate, the more conducive to improving the corrosion resistance of the coatings [2].

\subsection{Mechanism by Which ODA-GO Improves Corrosion Resistance in SMER Coatings}

Previous studies revealed that the addition of nanosheets to organic coatings can improve their corrosion resistance in the following five aspects: (1) Interface defects 
between nanoparticles and coatings can be reduced by changing the nanoparticle-organic polymer compatibility. (2) The bonding strength between an organic coating and its metal substrate can be enhanced by adding nanoparticles with certain functional groups. (3) By adding nanoparticles with special structures, the diffusion path of the corrosive medium immersing the coating can be effectively extended. (4) A good corrosion inhibition effect can be achieved by adding nanoparticles with special properties and constructing a highly hydrophobic surface by certain physical or chemical methods. (5) The addition of nanoparticles with special physical and chemical properties can effectively inhibit charge transfer at the metal/electrolyte interface [12,28-31].

For ODA-GO nanoparticles, good hydrophobicity led to good dispersibility in the SMER coating and effectively filled defects existing inside the SMER coating. This significantly reduced the water absorption of the coating (Figure 10). Moreover, the ODA-GO nanoparticles had high compatibility with the silicone-epoxy polymer matrix, which improved their interfacial adhesion and effectively enhanced the barrier effect of the coating (Figure 11). In addition, the ODA-GO nanoparticles had the advantages of high specific surface area and good dispersibility in the coating, which can lengthen the diffusion path of the corrosive medium into the interior of the coating and significantly enhance the physical barrier effect of the coating. At last, the anti-peeling performance of the coating applied on the steel is another important parameter determining the resistance of an organic coating to a corrosive medium. The ODA-GO coating had better cathodic disbonding resistance than the GO/SMER and pure SMER coatings, which also proves that the addition of ODA-GO can improve the coating's corrosion resistance. The schematic diagram of the anticorrosion mechanism for different coatings was shown in Figure 15.

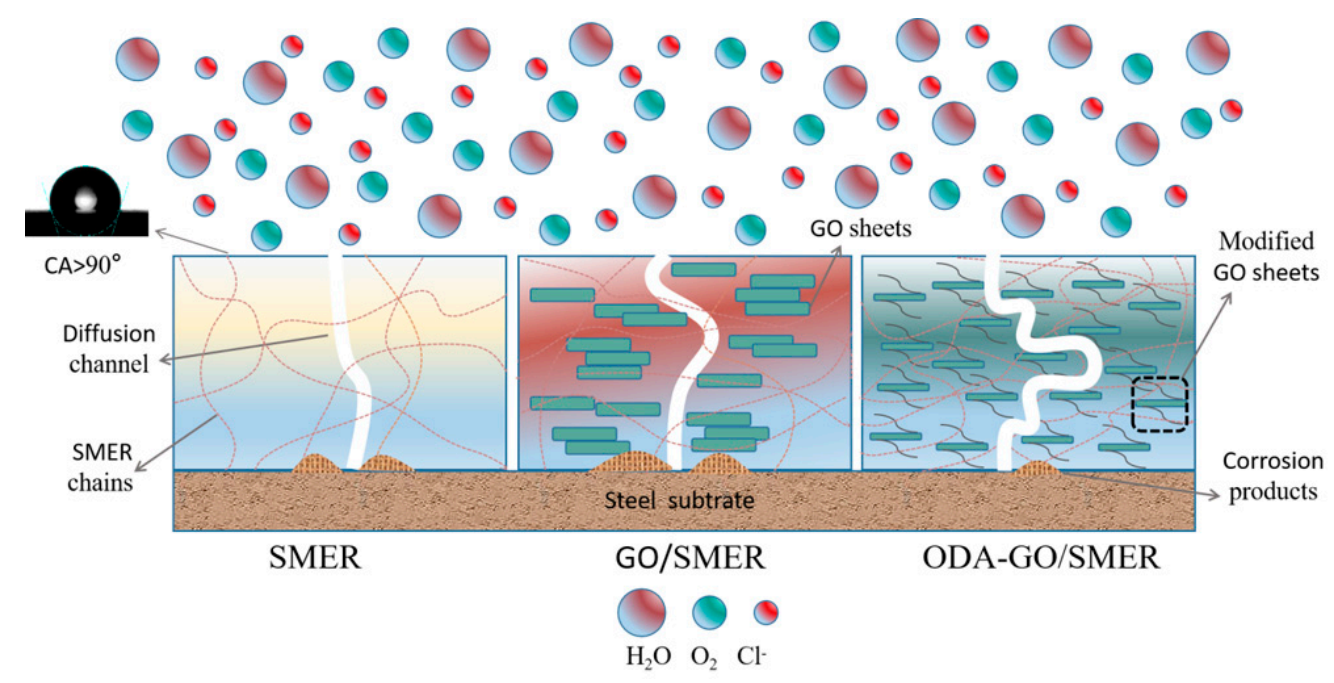

Figure 15. Schematic diagram of anti-corrosion mechanism for SEMR, GO/SMER and ODA-GO/SMER applied on the steel substrate.

Therefore, the ODA-GO/SMER coating exhibited better physical barrier properties in the EIS and salt spray tests than the GO/SMER coating and pure SMER coating. Additionally, it still had a higher low-frequency end impedance value and higher phase angle after 28 days of soaking in $3.5 \mathrm{wt} . \% \mathrm{NaCl}$ solution (Figures 12 and 13). The results also show that a $0.5 \mathrm{wt} . \%$ addition of ODA-GO to SMER will not effectively fill the interfacial defects existing in the coating, while a $2 \mathrm{wt} . \%$ addition of ODA-GO to a SMER coating is prone to agglomeration. When $1 \mathrm{wt} . \%$ ODA-GO was added to the SMER coating, it had excellent physical barrier properties, good interfacial compatibility, and exhibited the best anticorrosive properties. 


\section{Conclusions}

(1) XRD, FT-IR, Raman, XPS, SEM, and other characterization methods confirmed that the ODA successfully grafted onto the GO surfaces by chemical bonding with oxygencontaining groups of the GO, which gave the ODA-GO material high hydrophobicity and good dispersibility in SMER coating.

(2) The good compatibility of ODA-GO with the SMER coating effectively enhanced their interfacial adhesion, reduced the water absorption of the coating, prolonged the diffusion path of the corrosive medium inside the coating and strengthened the antipeeling performance of the coating applied on the steel. Hence, the physical barrier effect and corrosion resistance of the SMER coating were comprehensively improved.

(3) With 1 wt.\% addition of ODA-GO to SMER, the composite coating on the carbon steel matrix gave the best anticorrosive effect.

Author Contributions: F.H. designed experiments; W.Y. and J.Z. carried out experiments and wrote the manuscript; F.H., Q.H. and J.L. analyzed experimental results; Q.H. and F.H. revised the manuscript. All authors have read and agreed to the published version of the manuscript.

Funding: This research was funded by the China National Natural Science Foundation (grant number: 51871172).

Institutional Review Board Statement: Not applicable.

Informed Consent Statement: Informed consent was obtained from all subjects involved in the study.

Data Availability Statement: The data presented in this study are available in the article.

Conflicts of Interest: The authors declare no conflict of interest.

\section{References}

1. Cui, M.J.; Ren, S.M.; Zhao, H.C.; Xue, Q.J.; Wang, L.P. Polydopamine coated graphene oxide for anticorrosive rein-forcement of water-borne epoxy coating. Chem. Eng. J. 2018, 335, 255-266. [CrossRef]

2. Parhizkar, N.; Shahrabi, T.; Ramezanzadeh, B. A new approach for enhancement of the corrosion protection properties and interfacial adhesion bonds between the epoxy coating and steel substrate through surface treatment by covalently modified amino functionalized graphene oxide film. Corros. Sci. 2017, 123, 55-75. [CrossRef]

3. Kumar, S.A.; Sasikumar, A. Studies on novel silicone/phosphorus/sulphur containing nano-hybrid epoxy anticorro-sive and antifouling coatings. Prog. Org. Coat. 2010, 68, 189-200. [CrossRef]

4. Mert, B.D. Corrosion protection of aluminum by electrochemically synthesized composite organic coating. Corros. Sci. 2016, 103, 88-94. [CrossRef]

5. Yu, Z.; Di, H.; Ma, Y.; Lv, L.; Pan, Y.; Zhang, C.; He, Y. Fabrication of graphene oxide-alumina hybrids to reinforce the anti-corrosion performance of composite epoxy coatings. Appl. Surf. Sci. 2015, 351, 986-996. [CrossRef]

6. Zheng, H.P.; Shao, Y.W.; Wang, Y.Q.; Meng, G.Z.; Liu, B. Reinforcing the corrosion protection property of epoxy coat-ing by using graphene oxide-poly(urea-formaldehyde) composites. Corros. Sci. 2017, 123, 267-277. [CrossRef]

7. Ramezanzadeh, B.; Ahmadi, A.; Mahdavian, M. Enhancement of the corrosion protection performance and cathodic delamination resistance of epoxy coating through treatment of steel substrate by a novel nanometric sol-gel based silane composite film filled with functionalized graphene oxide nanosheets. Corros. Sci. 2016, 109, 182-205. [CrossRef]

8. Liu, X.; Shao, Y.; Zhang, Y.; Meng, G.; Zhang, T.; Wang, F. Using high-temperature mechanochemistry treatment to modify iron oxide and improve the corrosion performance of epoxy coating -II. Effect of grinding temperature. Corros. Sci. 2015, 90, 463-471. [CrossRef]

9. Liu, X.; Shao, Y.; Zhang, Y.; Meng, G.; Zhang, T.; Wang, F. Using high-temperature mechanochemistry treatment to modify iron oxide and improve the corrosion performance of epoxy coating -I. High-temperature ball milling treat-ment. Corros. Sci. 2015, 90, 451-462. [CrossRef]

10. Luo, H.L.; Ao, H.Y.; Peng, M.X.; Yao, F.L.; Yang, Z.Y.; Wan, Y.Z. Effect of highly dispersed graphene and graphene ox-ide in 3D nanofibrous bacterial cellulose scaffold on cell response: A comparative study. Mater. Chem. Phys. 2019, 235, 121774. [CrossRef]

11. Sahoo, S.K.; Padhiari, S.; Biswal, S.K.; Panda, B.B.; Hota, G. $\mathrm{Fe}_{3} \mathrm{O}_{4}$ nanoparticles functionalized GO/g-C3N4 nanocompo-site: An efficient magnetic nanoadsorbent for adsorptive removal of organic pollutants. Mater. Chem. Phys. 2020, 244, 122710. [CrossRef]

12. Sari, M.J.; Shamshiri, M.; Ramezanzadeh, B. Fabricating an epoxy composite coating with enhanced corrosion re-sistance through impregnation of functionalized graphene oxide-co-montmorillonite Nanoplatelet. Corros. Sci. 2017, 129, 38-53. [CrossRef]

13. Ramezanzadeh, B.; Bahlakeh, G.; Ramezanzadeh, M. Polyaniline-cerium oxide (PAni-CeO2) coated graphene oxide for enhancement of epoxy coating corrosion protection performance on mild stee. Corros. Sci. 2018, 137, 111-126. [CrossRef] 
14. Stankovich, S.; Piner, R.D.; Nguyen, S.T.; Ruoff, R.S. Synthesis and exfoliation of isocyanate-treated graphene oxide nanoplatelets. Carbon 2006, 44, 3342-3347. [CrossRef]

15. Niyogi, S.; Bekyarova, E.; Itkis, M.E.; McWilliams, J.L.; Hamon, M.A.; Haddon, R.C. Solution Properties of Graphite and Graphene. J. Am. Chem. Soc. 2006, 128, 7720-7721. [CrossRef]

16. Lin, Z.; Liu, Y.; Wong, C.-P. Facile Fabrication of Superhydrophobic Octadecylamine-Functionalized Graphite Oxide Film. Langmuir 2010, 26, 16110-16114. [CrossRef]

17. Zhao, Y.; Ding, H.; Zhong, Q. Synthesis and characterization of MOF-aminated graphite oxide composites for $\mathrm{CO}_{2}$ capture. Appl. Surf. Sci. 2013, 284, 138-144. [CrossRef]

18. Jahandideh, S.; Shirazi, M.J.S.; Tavakoli, M. Mechanical and thermal properties of octadecylamine-functionalized graphene oxide reinforced epoxy nanocomposites. Fibers Polym. 2017, 18, 1995-2004. [CrossRef]

19. Cao, N.; Zhan, Y. Study of Reduced Graphene Oxide Preparation by Hummers' Method and Related Characteriza-tion. J. Nanomater. 2015, 2, 1-5.

20. Compton, O.C.; Nguyen, S.T. Graphene Oxide, Highly Reduced Graphene Oxide, and Graphene: Versatile Building Blocks for Carbon-Based Materials. Small 2010, 6, 711-723. [CrossRef]

21. Das, A.K.; Srivastav, M.; Layek, R.K.; Uddin, M.E.; Jung, D.; Kim, N.H.; Lee, J.H. Iodidemediated room temperature re-duction of graphene oxide: A rapid chemical route for the synthesis of a bifunctional electrocatalyst. J. Mater. Chem. A 2014, 2, 1332-1340. [CrossRef]

22. Wang, C.; Lan, Y.; Yu, W.; Li, X.; Qian, Y.; Liu, H. Preparation of amino-functionalized graphene oxide/polyimide composite films with improved mechanical, thermal and hydrophobic properties. Appl. Surf. Sci. 2016, 362, 11-19. [CrossRef]

23. Stankovich, S.; Dikin, D.A.; Piner, R.D.; Kohlhaas, K.A.; Kleinhammes, A.; Jia, Y.; Wu, Y.; Nguyen, S.T.; Ruoff, R.S. Syn-thesis of graphene-based nanosheets via chemical reduction of exfoliated graphite oxide. Carbon 2007, 45, 1558-1565. [CrossRef]

24. Ramezanzadeh, B.; Ghasemi, E.; Mahdavian, M.; Changizi, E.; Moghadam, M.M. Characterization of covalently-grafted polyisocyanate chains onto graphene oxide for polyurethane composites with improved mechanical properties. Chem. Eng. J. 2015, 281, 869-883. [CrossRef]

25. Wang, P.; Zhang, D.; Qiu, R.; Wan, Y.; Wu, J. Green approach to fabrication of a super-hydrophobic film on copper and the consequent corrosion resistance. Corros. Sci. 2014, 80, 366-373. [CrossRef]

26. Bi, H.; Sykes, J. Cathodic disbonding of an unpigmented epoxy coating on mild steel under semi- and full-immersion conditions. Corros. Sci. 2011, 53, 3416-3425. [CrossRef]

27. Xiao, K.; Dong, C.; Zhang, X.; Wu, J.; Xu, L.; Lin, Y.-C. Corrosion of carbon steel under epoxy-varnish coating studied by scanning Kelvin probe. J. Wuhan Univ. Technol. Sci. Ed. 2012, 27, 825-829. [CrossRef]

28. Ramezanzadeh, B.; Ghasemi, E.; Mahdavian, M.; Changizi, E.; Moghadam, M.M. Covalently-grafted graphene oxide nanosheets to improve barrier and corrosion protection properties of polyurethane coatings. Carbon 2015, 93, 555-573. [CrossRef]

29. Cao, X.K.; Huang, F.; Huang, C.; Liu, J.; Cheng, F. Preparation of grahene nanoplate added zinc-rich epoxy coatings for enhanced sacrificial anode-based corrosion protection. Corros. Sci. 2019, 159, 108120. [CrossRef]

30. Golru, S.S.; Attar, M.; Ramezanzadeh, B. Studying the influence of nano- $\mathrm{Al}_{2} \mathrm{O}_{3}$ particles on the corrosion performance and hydrolytic degradation resistance of an epoxy/polyamide coating on AA-1050. Prog. Org. Coat. 2014, 77, 1391-1399. [CrossRef]

31. Qi, K.; Sun, Y.M.; Duan, H.W.; Guo, X.P. A corrosion -protective coating based on a solution-processable poly-mer-grafted graphene oxide nanocomposite. Corros. Sci. 2015, 98, 500-506. [CrossRef] 